\title{
The Economic Implications of Kinship: Small Entrepreneurs in Guangzhou Garment Industry
}

\author{
Chong Gao \\ Hong Kong Shue Yan University
}

\begin{abstract}
Over the past decades, the anthropological study of Chinese kinship has tended to emphasize its sociocultural functioning in organizing and structuring Han Chinese society. Among the few studies of Chinese kinship and Chinese entrepreneurship, the presence of, and preference for, kinship connections in Chinese businesses is usually considered as the immediate product of long-standing kinship traditions in Chinese culture or as the response to certain social constraints. It seems that the economic benefits and returns of the inclusion of kinship relations in business affairs are underestimated and even neglected. This study focuses on why, how and to what extent kinship is involved in concrete and ongoing business processes and explores how the mobilization of kinship brings competitive advantages for small entrepreneurs. The ethnographic data collected shows that the businessmen tend to re-conceptualize kinship with reference to economic rationality and to exploit the economic potential of kinship purposefully. In so doing, economic interests are highlighted and included in the explanations of the deep involvement of Chinese kinship in business affairs.
\end{abstract}

\section{INTRODUCTION}

Since the 1970s, the business success of both overseas Chinese and entrepreneurs in Mainland China has triggered intensive academic exploration. Scholars have attempted to explain from different perspectives the reasons for the economic miracle created by the Chinese. Inspired by Max Weber's comparative study of cultural traditions and the rise of capitalism $(1958,1964)$, some studies have examined the possible influences of Han Chinese culture in economic development and have sought for the positive effect of certain Chinese cultural elements. Those positive cultural values detected and identified include pragmatism, familism, respect for authority, desire for autonomy, use of guanxi, high achievement motivation, nepotism, industriousness, diligence and so on (Wong, 1996a, 1996b, 1986; Hamilton, 1996; Redding, 1990). In this manner, Han Chinese kinship is linked to modern business activities originating in the West. In many cases, the intensive inclusion of kinship relations in business affairs is believed to be a prominent feature, as well as a driving force, in Chinese business.

However, such practices in Western management science and business studies are labeled nepotism and are usually believed to be negative in business. From this perspective, strong 
kinship solidarity may bring difficulties to the working of rational management. In Western business communities, it is widely accepted that feelings and emotions should be excluded from normal business operations, as they do not conform to economic rationality. If so, one may raise some immediate questions: why is nepotism apparently a positive cultural value in Chinese entrepreneurship? Do the Chinese have a higher understanding of kinship solidarity, through which they translate nepotism into a positive force? Why do Chinese prefer to get their relatives involved in their businesses?

Generally speaking, there are two major research streams in the social sciences that are devoted to answering these questions. On one hand, the presence of kinship in entrepreneurship is considered the legacy of the long-standing Han Chinese cultural tradition of prioritizing and benefiting relatives. On the other hand, some studies attribute the extensive use of kinship as a response to specific structural constraints. In this regard, the Chinese tend to take advantage of kinship to handle difficulties originating in hostile social environments.

The cultural explanation concentrates on the strength of cultural value systems as capable of directing human behavior. It seems that the Han Chinese, once they start their own businesses, have been regulated by their culture to bring in their relatives without hesitation. In other words, the involvement of kinship in business is the immediate outcome of traditional Han Chinese kinship obligations (Cohen, 2005; Santos, 2006; Watson, 1982).

The Han Chinese have a long tradition of considering their families and relatives in terms of insiders and outsiders. Based on the configuration of differentiation among one's various relatives, one may have different attitudes or preferences and take different actions to relatives respectively. This practice reflects the general principle of kinship in China-the differential mode of association (chaxugeju) (Fei 1992, pp. 60-70). According to the working of this kinship principle, Chinese entrepreneurs take for granted the invitation to their families and relatives to join in their businesses. In this way, it is important for Chinese businessmen to fulfill kinship obligations and take responsibility to help relatives. It is assumed that economic efficiency in business operations is subordinated to cultural values and duties among the Chinese.

However, a few empirical studies indicate that Chinese kinship ethics and obligations have been subject to considerable changes with the introduction of market economy in the "opening and reform era". For instance, affinity may provide more support and resources than consanguinity for entrepreneurial couples in their business activities in big cities like Tianjin so that the patriarchal tradition faces big challenges ( $\mathrm{Li}, 1997)$. In rural China, the introduction of market logic has also led villagers to replace to some extent the traditional exchange of labor among relatives with hired labor, due to various difficulties and troubles associated with economic calculations of human feelings (renqing) (Yang, 1994). Such cases show that the penetration of economic rationality and market mentality may lead to the decline of Chinese kinship in terms of regulating and directing people's behavior.

On the other hand, structural explanations suggest that specific structural factors may promote the introduction of families and relatives in business. Under given social conditions, entrepreneurs with disadvantaged social origins may face various social constraints and have no choice but to turn to families or relatives for help, such as has been the case among Taiwan businessmen (Greenhalgh, 1994). One study of entrepreneurship in rural China also reveals that kinship networks have a positive effect on the entrepreneurial rate and business size of private enterprises, as kinship solidarity and trust help protect property rights and lower transaction costs in a society without sufficient legal protection and rational market mechanisms (Peng, 2004). This structural debate implies that the result would be different if the situation changed. That is 
to say, Chinese entrepreneurs may not hold to the cultural preference for kinship in business and are likely to exclude families or relatives if conditions allow. The problem is whether or not the use of kinship is really the only alternative in such social conditions.

Both cultural and structural debates may lead to an over-socialized paradigm, in which it is taken for granted that the Chinese entrepreneur as social actor will take expected action driven by a given cultural legacy or by structural factors. His/her behavior is seen to be strictly regulated by the cultural tradition or social context in which it is embedded. Such a perspective neglects the complex reasoning and cognitive processes involved in human action and leaves no room for individual calculation.

In order to have a better understanding of the role of kinship in Chinese entrepreneurship, this study attempts to locate the practice along a continuum. One end of this continuum is that of action driven exclusively by kinship obligations, while the other end is that of action dominated purely by economic rationality. In theory, the actual conduct of businessmen in terms of kinship involvement should be situated on this continuum. The implications of this are two-fold. Firstly, it dismantles the culture-economy dichotomy and conceives of the economy as an integral part of society. Secondly, the application of cultural embeddedness to the study of economy highlights the strength of a holistic viewpoint in anthropology and may provide insight into the understanding of economic action. In fact, human life itself is a complex whole, and its component parts, such as economy, should be understood within the entire picture.

This study concerns how entrepreneurs themselves conceptualize the use of kinship in their business startups and business operations, and how they mobilize kinship to achieve competitive advantage in their entrepreneurial practices. That is to say, the focus of this study is on the strategic use of kinship conditioned by market mentality "on the ground".

\section{METHODOLOGY}

The strength of anthropology in the study of entrepreneurship lies in "its method of gathering data-through the observation of and interaction with the subject of the study" and "its holistic approach, focused on culture" (Montoya 2000, pp. 334-335). The long-standing participant observation and deep involvement in the daily life of the business community empower ethnographers to understand human action as well as its complicated cultural meanings (Tian, 2010). The data for this study has been collected through ethnographic fieldwork in a suburban industrial cluster of Guangzhou, the capital city of Guangdong Province, China, where hundreds of garment factories and related factories are located. The fieldwork was conducted in the year 2002 and 2003, with two follow-up fieldtrips in January 2006 and July 2007, respectively, to update some information.

With the help of local contacts established during my Bachelor and Master degree study in Guangzhou, I was introduced to many businessmen in the large-scale garment production cluster at an early stage of fieldwork. By means of guanxi practice and frequent exposure to the business community, I had the opportunity to approach factory owners from different regions and social origins. With prior permission from some of them, I usually stayed in their offices or on the shop-floor to observe what actually happened in everyday business operations and to communicate with anyone who would like to talk. In addition, some friendly key informants allowed me to shadow them and give me opportunity to experience concrete business processes, such as meetings for business purposes, eating and sharing inside stories of business in restaurants, interacting and negotiating between employers and employees, and so on. In this 
manner, general data on the everyday practice of entrepreneurship and various aspects of the garment business was collected through participant observation. Apart from this, semi-structured interviews were conducted among those key informants who had rich knowledge of economic and social issues in the fieldwork site. Interviews were usually carried out on the shop floor, in offices, and in chophouses and restaurants. In total, 41 migrant entrepreneurs who were not local residents but who ran garment-related factories in the suburban industrial cluster were interviewed. These factories were usually small or medium sized, with dozens of workers.

This study concentrates on stories of starting and running businesses and on how kinship-inbusiness issues were dealt with in the entrepreneurial process. The entrepreneurs as business people usually faced the dilemma of having, on one hand, to take action according to economic rationality, as the maximization of profits was their "calling"; while, on the other hand, as nodes of kinship networks, kinship obligations were often taken into consideration in their business decisions. The first section will look at how they re-conceptualized kinship ethics and obligations when they entered the business world. The second section concentrates on the concrete economic benefits they may have enjoyed from the adoption of relatives in business. The conclusion is in the third section.

\section{KINSHIP FIRST OR BUSINESS FIRST?}

In theory, there is internal tension between kinship and position in business. Kinship status is ascribed through marriage or reproduction, while job position is achieved by one's own efforts and competence. Nepotism may erode the principle of fair play in the work place. When the business firm enjoys the participation of relatives, it also must take measures to avoid negative effects that may come with kinship interference (Tian et. al., 2010, pp. 534-539). The small entrepreneurs interviewed in fieldwork usually had a clear conception of the advantages and defects of recruitment through their kinship network as well as through the local labor market. They attempted to control the negative effects of each recruitment practice and maintain the balance between kinship obligations and market principles. Some of them began to realize that the criteria for recruitment for a factory should be individual competence. Some factory owners were afraid that incompetent relatives would affect the competitive power of their factories. They would perhaps extend such competence criteria to their relatives who wanted to work in their factories. Mr. Cao explained his understanding of kinship in business operation:

"There are some relatives in my factory, such as my uncle and cousins. I offer them opportunities and will arrange for them to do what they can do. If they are not competent, I will ask them to leave. I have to survive in market competition. My uncle has left for his hometown because he is not competent. The son of my uncle has learned some sewing skills but his technique is just so-so. Now I am beginning to manufacture garments for shopping malls and the requirements for quality are rising. If he does not adapt to such changes, he has to leave my factory and find a job in some factory with lower requirements." (interview with Mr. Chao)

Even if some capable relatives are hired in their factories, factory owners also have to consider how to establish fair play. As relatives tend to make requests for special treatment, kinship may foster privileges. In a factory this 'unfair' circumstance will harm normal operations 
because the other workers will take it badly and initiate internal conflicts. Mr. Zheng's younger brother and sister acted as sewing workers in his factory, and he believed that the other workers would listen to you if you regulated your relatives fairly. In order to demonstrate the principle of fair play, some factory owners hired their friends to regulate their workers. Mr. Xiao talked about his choice of action like this:

"I invited one of my good friends to regulate my factory. Some of my relatives work in it. If I managed it by myself, I would have to take care of their mianzi ('face'). But if I really do that, the others may feel it is unfair. If most workers in the factory are your relatives, the other workers may feel isolated and will leave." (interview with Mr. Xiao)

As the failure to maintain a steady labor force brings negative effects on business operations, the factory owners usually sought efficient solutions to lower the presence of kinship. They had a clear understanding of this potential crisis along with that of nepotism, which indicates that they would not comply with kinship obligations at the expense of their businesses. Under some conditions, a few entrepreneurs sensed the pressure to hire relatives so they tended to take strategic measures to exclude them and to minimize the negative influence of kinship on business.

It is likely that some entrepreneurs had to hire excess workers for the sake of kinship obligations at the initial stage. When they came to the negative impact on the business performance of their factory and could not bear the loss, they often chose to fire excess kinworkers. This practice is not different from what Western employers do in economic crises. Mr. Xia experienced such a difficult time:

"The packing section in my factory only needs three or four workers but there are eight now. Why? They are all my relatives and village fellows. Once they get to know that I have opened a garment factory here, they request to join my factory. My hometown is poor so they just want to 'find rice' (zhao wan fan chi). If I refuse, they may censure me for neglecting 'human emotions' (bu jiang renqing). But they know nothing about garment production, so I have no choice but to ask them to work in the packing section for some weeks. Finally, I must compete with others in the market, so I cannot look after them like this." (interview with Mr. Xia)

Mr. Xia dismissed one half of his staff, all his relatives, in the packing section of his factory three months later. During the slow season, profits decreased quickly so he had to take immediate action to cut loss. In the business world, profits go beyond kinship obligation. This makes sense in various human societies, including that of China.

In order to lower the negative impact of kinship on business, some entrepreneurs even refused to accept relatives into their factories. Alternatively, some of them would rather offer monetary support free of charge as fulfillment of kinship obligations than hire relatives as workers. Mr. Cai spelled out the alternative measures he took to balance kinship commitments and business rationality:

"My brother cannot find job in our hometown, but I would rather give him some money than ask him to work in my factory. It is the practice of human obligation 
(renqing) to give money. It is simple. But it will be troublesome to turn him into one of the workers in the factory. Business is business, and it should not blend with renqing." (interview with Mr. Cai)

No matter how entrepreneurs choose to deal with kinship obligations, it is not difficult to find that they get to know both the positive and negative sides of kinship, in relation to intensive economic calculations. For these migrant entrepreneurs, nepotism may be employed as an instrumental response to the jumbled and insecure social context. When they find the negative side of nepotism, they will apply market principles and restrict, or even reduce, the number of relatives in their factories. They tend to evaluate individual competence and the need of their factory before they decide whether or not to offer a relative a job. In addition, they will fire kinworkers if their existence may cause some loss to their business. It is not surprising to find that kinship obligation is subordinated to economic rationality in terms of kinship in business.

\section{ECONOMIC RETURNS FROM THE PARTICIPATION OF KINSHIP}

As the presence of kin is conditioned by economic calculation, it is not difficult to find that the participation of relatives really brings some additional economic benefits to entrepreneurs. For instance, the supply of labor from a kinship network may provide a stable labor force in the factory and enable small entrepreneurs with small startup capital to get inexpensive helping hands. Driven by kinship obligations, some relatives were willing to work harder than other employees and promote the output and productivity. The closed subcontract network based on kinship may generate a collaborative effect and help an individual factory to overcome the uneven distribution of purchase orders over peak and slow seasons.

Although the participation of relatives in business is colored by kinship emotions and obligations, it is indeed a good deal in the eyes of the entrepreneurs. This is far away from the long-standing tradition of mutual-aid (huxiang bangmang) among relatives. The entrepreneurs stated clearly that the reason they chose to invite some relatives or country fellows to their factories lay in their shortage of money to hire capable workers in the open labor market. Labor is one of the most important factors of production and it is especially significant in such laborintensive industries as garment production. How to reduce the cost of labor and maintain a steady labor force is thus at the core of the garment making business. With the exceptions of investment in sewing machines and housing rents, the labor cost constitutes 30 to 40 percent of running expenses of a factory. Access to labor through the kinship network thus becomes the source of competitive capacity for migrant entrepreneurs who set up garment factories.

Firstly, hiring relatives helps to reduce labor costs. These capital-short migrant entrepreneurs usually do not have enough money to pay workers during the first phase of business startup, so they have to turn to their relatives or country fellows for help. The majority of factory owners visited during fieldwork start their business with no more than fifty thousand RMB. The average monthly salary for one sewing worker was about 1500 RMB. In such a situation, it is unrealistic for small entrepreneurs to hire workers at market price due to their lack of capital. Generally speaking, the notion of mutual aid enables their relatives or country fellows to accept a delay in receiving wages for some months; then too, the jobs offered are usually their first industrial jobs, so they do not know the market value of their labor. They do not know the average wage level in the host society and only compare the wage the factory owners offer with their incomes in the village. Thus they are more likely to accept low wages than job-seekers in the local labor market. 
They usually consider the job offered as a golden opportunity and accept it without bargaining about wages. One of the informants affirmed this:

"As soon as your relatives or friends in your hometown get to know that you are opening a garment factory, they will actively contact you and hope to work in your factory. Anyway, they trust their acquaintances when they find jobs outside." (interview with Mr. He)

Under such circumstances, hiring relatives or country fellows helps migrant entrepreneurs get labor supply at low cost.

When they make good preparations for their new factories, they usually return to their hometowns in person; or they may just call their families to send some relatives or village fellows who want to work outside - it is easy for them to look for workers in their hometowns (Solinger, 1998:10). For instance, when Mr. Weng, a migrant from Tongcheng, Anhui Province, decided to operate his own factory at the end of 2002, he made a phone call to his younger brother in Anhui and asked him to bring tens of workers. The workers were found within a day and arrived in Guangzhou three days later.

Secondly, the lack of labor in the Pearl River Delta in recent years had made it difficult for newly-established factories to hire workers in the local labor market, so that the sole strategy for some new factory owners to obtain their labor supply is through relative or country fellow networks. Since the year 2002, the shortage of labor and the difficulty of hiring workers has become a popular topic. It was said that the shortage of workers was due to factory owners from Hubei, especially from Tianmen County of Hubei, who cheated some workers, defaulted on salary payment and escaped. This bad behavior ruined the fame of the garment production district among migrant workers, so that some of them were reluctant to go to the Pearl River region. The outbreak of SARS in Guangzhou in the first half of 2003 can be considered as having been another obstacle to finding labor.

The workers had several choices among the various garment factories, so they did not like to find jobs in new factories as most new migrant entrepreneurs had limited startup capital. Further, they did not offer competitive wages or good working and living conditions for workers. Also, new factories lacked a good reputation among workers that might attract them. Thus, as some factory owners did not offer attractive salaries, they had to mobilize relatives or country fellows.

The economic benefits of kinship go beyond the supply of labor. Some factory owners believed that their relatives or country fellows contributed more to their businesses than other workers. The obligation among relatives or country fellows usually compelled them to work harder than others in the factory to indicate that 'blood is thicker than water'. The emotion among relatives or country fellows was transformed into work performance in the factory. For instance, when some urgent orders had to be completed within a short period of time, factory owner hoped that workers would cooperate. The overtime work driven by monetary rewards usually did not work when it lasted two or three days. The workers might be exhausted after working day and night in peak season, and might choose to go to sleep rather than to work for prompt delivery. In their words, "what we sell is just labor, not human life". Even if workers from other places refused to work, the factor owner's relatives and country fellows usually had to continue. 
The willingness to engage in extra work is an embodiment of renqing (human feeling) among relatives. Mr. Dai even urged his workers to continue working for more than 30 hours without stop, in order to complete an order in two days. When there were about 500 garments left for sewing, some workers could not endure the workload and went to bed without sanction. Mr. Dai was vexed, but he had no way to deal with the situation. It was his relatives (including his wife, uncle and aunt) and some village fellows who persisted in the work. With their help, he delivered the goods on time and avoided compensating for delays in delivery. The help from relatives and village fellows not only earned more money for him but also decreased his business losses.

In addition to kinship as source of labor, some factory owners attempted to take advantage of existing kinship networks to weave a subcontract network when they happened to have some relatives in the same industry. The production capacity of a given factory may not match the rise and fall of the amount of its orders from time to time. Sometimes the size of an order was beyond the factory's processing capacity. It was also not uncommon that one factory did not get any order to handle for some days. Subcontracting networks are necessary to handle orders flexibly during different seasons. Generally speaking, the period from June to September was the slow season, during which the majority of garment factories did not get enough work to do from wholesale markets. Some had to lay off workers temporarily and close doors temporarily during this period. During the rush season, as most garment factories had fewer than 50 workers, factory owners did not dare to accept large orders due to the requirement for punctual delivery. In other words, they were in danger of losing good opportunities to make money. In order to grasp these opportunities they would call on their relatives who also had garment factories to cooperate.

Subcontracting facilitates flexibility. Through subcontracting networks, a factory may receive a large order, distribute work among its network members and thereby receive support from other factories. If this works well, it is of mutual benefit to all, and factories in such subcontracting networks attain competitive advantages over individual factories without such networks. For instance, Mr. Dai's aunt's husband acted as manager in a large-scale garment factory in Guangzhou, which usually landed large foreign orders. As soon as Mr. Dai's factory had no work, he would go to that factory to request some work to do. In this way, he made good use of the productivity of his factory and gained a better profit margin than his competitors.

Kinship is believed to be the best basis on which to construct a subcontracting network. Although subcontracting is mutually beneficial, each party may be afraid that others will cheat $\mathrm{him} / \mathrm{her}$. It is impossible for one to monitor the others. The functioning of the subcontracting network depends on strong ties, so relatives are the best choice. Migrant entrepreneurs' chain migration is based on their kinship networks (Ke, 1993), which facilitates congregation of relatives in a specific industry. With this cultural mechanism, successful migrant entrepreneurs in the fieldwork site often gave a hand to those relatives who wanted to follow them and open garment factories. Mr. Jin believes that relatives could be transformed into advantages in business:

"If you have many siblings, you can mobilize all of them to open garment factories here. As long as one of you receives many orders, he/she may help the others make money. In rush season, you dare to accept a large order while all the siblings help each other in low season." (interview with Mr. Jin)

Three factory owners - Mr. Lan, Mr. Liang and Mr. Mao - established a subcontracting network based on their kinship relationship. Mr. Lan and Mr. Mao had married two sisters. The 
two families started embroidery factories in Nanching in the year 2001. Mr. Liang, the sisters' younger brother, learned of the embroidery business and planned to follow them. He got support from his sisters and their families when he started his own factory. When they gathered and discussed how to conduct business, they promised to subcontract some work to each other if one of them got large orders. They all agreed not to extract profits from this subcontracting work. It is obvious that the subcontract network based on kinship is helpful for small entrepreneurs to bear the risk in business and secure more profits among the relatives.

\section{CONCLUSION}

As China does not experience a large scale rationalization process to exclude kinship obligations and human feelings from business operation, Chinese entrepreneurship is often misunderstood. The presence of relatives in business is quoted as strong evidence to prove that kinship plays an important role in the success of Han Chinese businessmen.

However, the stories of migrant entrepreneurs in suburban Guangzhou reveal that kinship has no determinative impact on business success. Before they adopt relatives in their business, they do the rational calculating of the resources available and the possible economic rewards of kinship. It is not difficult to get a stable labor supply and other advantages through mobilization of a kinship network. However, the premise of the introduction of relatives into business is not due to traditional kinship obligation but real economic interest. Entrepreneurs usually consider whether or not to hire a specific relative with reference to his/her individual competence. The choice of strategy is ultimately determined by the necessity of establishing market advantage, rather than purely following kinship ethics or obligations. If the presence of some relatives affects the pursuit of profits or leads to business loss, the entrepreneurs may take action to remove them from their factory and minimize the possible negative effect. Their conduct of business thus does not look significantly different from that of their counterparts among Western capitalists.

Entrepreneurs consider the rule of profit maximization as the basic criteria in judging various issues of business operation. The instrumental use of kinship is nothing but one of a number of business strategies, and the kinship obligations have to some extent been translated into economic collaboration. Kinship is not an independent variable which has direct impact on business operation. Instead, the strength of kinship obligations in regulating human behavior is eroding with the penetration of economic rationality. The principle of maximization of profits dominates the choice of strategies.

In addition to the theoretical implications in kinship studies, this study may also offer some inspiration to business researchers and business operators. Firstly, it is not uncommon to take into account of some "non-economic factors," like kinship, ethnicity, trust, and so on, in business practice and cultivate their economic potential as regulated by general business ethics. What is important for businessmen is to maximize economic profits in a legal and ethical manner, and they may make full use of all available instruments, including kinship, to attain this goal. Secondly, business operators must be aware of any kinship interference that may come with the intensive involvement of relatives, and must take effective measures to dismantle it. The negative impact of kinship on business is likely to rise if kinship involvement does not conform to economic principle.

Some limitations exist in this study. For instance, the measurements to evaluate exact economic rewards of kinship have not been formulated. The data and information in this study 
are insufficient to demonstrate gender variation in the use of kinship in business. If possible, some further studies may be oriented towards the design of some measurements and quantification of the actual economic contribution of kinship involvement. Apart from that, it would be worthwhile to put gender into perspective and highlight gender differentiation in a study centered on female entrepreneurs in further research.

\section{Acknowledgement}

The author extends his sincere thanks to the IJBA reviews for their encouraging comments and constructive suggestions to revise this article.

\section{REFERENCES}

Cohen, M. L. (2005). Kinship, Contract, Community and State: Anthropological Perspectives on China, Stanford: Stanford University Press.

Fei, X. T. (1992). From the Soil: the Foundations of Chinese Society, (trans. by G. H. Hamilton and W. Zheng) Berkeley: University of California Press.

Greenhalgh, S. (1994). De-Orientalizing the Chinese Family Firm. American Ethnologist, 21, (4), 746-775.

Hamilton, G. G. (1996). The Organizational Foundations of Western and Chinese Commerce: A Historical and Comparative Analysis. In G. Hamilton (ed.). Asian Business Network, Berlin and New York: Walter de Gruyter. pp.43-57.

Ke, Zhiming (柯志明) (1993). Taiwan Dushi Xiaoxing Zhizaoye de Chuangye, Jingying yu Chengchan Zuzhi-Yi Wufenpu Chengyi Zhizaoye wei Ge'an de Fenxi (台湾都市小型制造业的 创业，经营与生产组织——五分埔成衣制造业为个案的分析), Taibei: Zhongyang Yanjiuyan Minzuxue Yanjiusuo (台北: 中央研究院民族学研究所).

Li, Jiansheng (李建生) (1997). Jiating, Qinshu, Shangwu: Chengshi Funü De Tuidong Zuoyong - Cong Renleixue Jiaodu Dui Yi Zhongguo Chengshi Jinxing Shili Fenxi (家庭, 亲 属, 商务: 城市妇女的推动作用一从人类学角度对一中国城市进行实例分析). In Li Xiaojiang, Zhu Hong and Dong Xiuyu (eds.) (李小江, 朱虹, 董秀玉主编), Zhuliu Yu Bianyuan (主流与边缘). Beijing: Sanlian Shudian (北京: 三联书店). pp. 130-151.

Montoya, M. L. de. (2000). Entrepreneurship and Culture: The Case of Freddy, the Strawberry Man. In R. Swedberg (ed.), Entrepreneurship: The Social Science View, New York: Oxford University Press. pp. 332-355.

Peng, Y. S. (2004). Kinship Networks and Entrepreneurs in China's Transitional Economy. The American Journal of Sociology, 109, (5), 1045-1074. 
Redding, S. G. (1990). The Spirit of Chinese Capitalism, Berlin and New York: Walter de Gruyter.

Santos, G. D. D. (2006). The Anthropology of Chinese Kinship: A Critical Overview. European Journal of East Asian Studies, 5, (2), 275-333.

Solinger, D. J. (1998). Job Categories and Employment Channels among the "Floating Population". In G. O'Leary (ed.), Adjusting to Capitalism: Chinese Workers and the State, New York: M. E. Sharpe. pp.3-47.

Tian, R. G., Lillis, M. P. and Marrewijk, A. V. (2010). General Business Anthropology, Miami, FL: North American Business Press.

Tian, R. G. (2010). The Unique Contributions and the Unique Methodologies: A Concise Overview of the Applications of Business Anthropology. International Journal of Business Anthropology, 1, (2), 70-88.

Watson, J. L. (1982). Chinese Kinship Reconsidered: Anthropological Perspective on Historical Research. The China Quarterly, 92, December, 589-622.

Weber, M. (1958). The Protestant Ethic and the Spirit of Capitalism, New York: Charles Scribner's Sons.

Weber, M. (1964). The Religion of China: Confucianism and Taoism, New York: The Macmillan Company.

Wong, S. L. (1996a). Chinese Entrepreneurship and Economic Development. In B. L.

Mccormick and J. Unger (eds.), China after Socialism: In the Footsteps of Eastern Europe or East Asia? New York: M. E. Sharpe. pp.130-148.

Wong, S. L. (1996b). Chinese Entrepreneurs and Business Trust. In G. Hamilton (ed.). Asian Business Networks. Berlin and New York: Walter de Gruyter. pp.13-26.

Wong, S. L. (1986). Modernization and Chinese Culture in Hong Kong. The China Quarterly, 106, June, 306-325.

Yang, M. C. (1994). Reshaping Peasant Culture and Community: Rural Industrialization in a Chinese Village. Modern China, 20, (2), 157-179. 